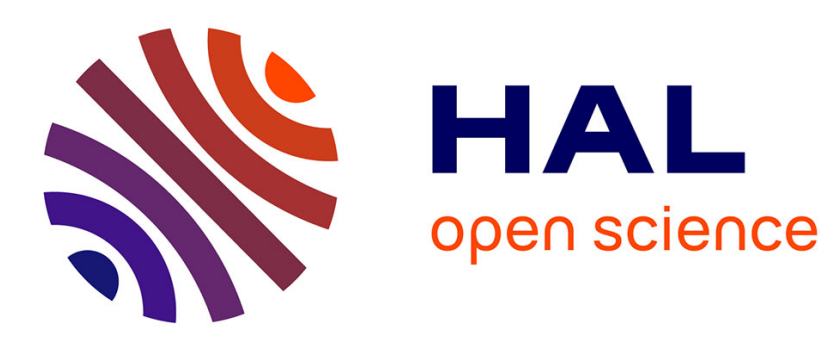

\title{
Assessing the effectiveness of supply flexibility sources: An empirical research
}

\author{
Elcio Mendonça Tachizawa, Cristina Gimenez
}

\section{To cite this version:}

Elcio Mendonça Tachizawa, Cristina Gimenez. Assessing the effectiveness of supply flexibility sources: An empirical research. International Journal of Production Research, 2009, 47 (20), pp.5791-5809. 10.1080/00207540802146122 . hal-00513038

\section{HAL Id: hal-00513038 https://hal.science/hal-00513038}

Submitted on 1 Sep 2010

HAL is a multi-disciplinary open access archive for the deposit and dissemination of scientific research documents, whether they are published or not. The documents may come from teaching and research institutions in France or abroad, or from public or private research centers.
L'archive ouverte pluridisciplinaire HAL, est destinée au dépôt et à la diffusion de documents scientifiques de niveau recherche, publiés ou non, émanant des établissements d'enseignement et de recherche français ou étrangers, des laboratoires publics ou privés. 


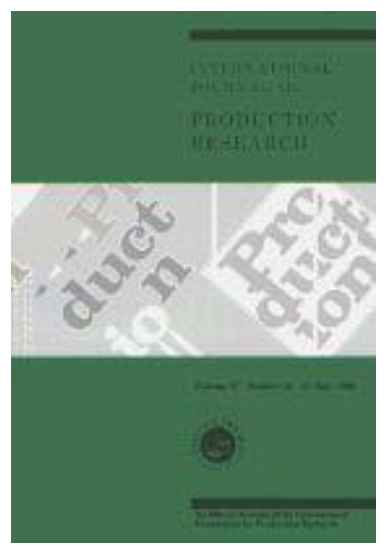

Assessing the effectiveness of supply flexibility sources: An empirical research

\begin{tabular}{|r|l|}
\hline Journal: & International Journal of Production Research \\
\hline Manuscript ID: & TPRS-2007-IJPR-0519.R2 \\
\hline Manuscript Type: & Original Manuscript \\
\hline Author: & 19-Mar-2008 \\
\hline Complete List of Authors: & $\begin{array}{l}\text { Tachizawa, Elcio; Universitat Pompeu Fabra, Department of } \\
\text { Economics and Business } \\
\text { Gimenez, Cristina; Universitat Ramon Llul - ESADE Business School, } \\
\text { Department of Operations and Innovation Management }\end{array}$ \\
\hline Keywords: & $\begin{array}{l}\text { FLEXIBILITY, PURCHASING, SUPPLY CHAIN MANAGEMENT, } \\
\text { EMPIRICAL STUDY }\end{array}$ \\
\hline Keywords (user): & FLEXIBILITY, PURCHASING \\
\hline &
\end{tabular}

\section{S ScholarONE" \\ Manuscript Central}




\title{
Article Type: Research paper
}

\section{${ }^{1}$ Assessing the effectiveness of supply flexibility sources: An empirical research}

\author{
E.M. TACHIZAWA*† and C. GIMÉNEZ
}

\author{
$\dagger$ Department of Economics and Business; Universitat Pompeu Fabra; Ramon Trias Fargas, 25- \\ 27, 08005 Barcelona, Spain; elcio.mendonca@upf.edu, tel. +34 93542 1621. Corresponding author. \\ $\$$ Department of Operations and Innovation Management; ESADE Business School - \\ Universitat Ramon Llull; Av. de Pedralbes, 60-62, 08034 Barcelona, Spain; cristina.gimenez@esade.edu, \\ tel. +34932806162 .
}

This paper focus on supply flexibility, i.e. the ability of the purchasing function to respond in a timely and cost effective manner to changing requirements of purchased components, in terms of volume, mix and delivery date. It is argued that managerial actions may have different effects on different dimensions of supply flexibility. More specifically, we aim to answer the following research questions: What is the effectiveness of the different supply flexibility sources? Are there any variables that could moderate the relationship between supply flexibility sources and supply flexibility? We perform a regression analysis of the effectiveness of the different supply flexibility sources. In particular, we conduct a stepwise regression, setting the supply flexibility sources as independent variables, and the three dimensions of supply flexibility (identified in the factor analysis) as dependent variables. In order to refine the models and increase the generalizability of the study, some control variables (i.e. firm revenue and flexibility focus) are also included in the regression analysis. Results suggest that each dimension of supply flexibility is associated with a particular group of sources, i.e. the sources used to increase a certain dimension of supply flexibility (e.g. supplier responsiveness) may be ineffective for another dimension (e.g. adaptability).

Keywords: Sourcing, purchasing, Spain, empirical, survey

${ }^{1}$ The authors gratefully acknowledge the significant contribution of the reviewers. The authors also thank AERCE for facilitating the access to its members. Cristina Giménez acknowledges financial support from research grant BEC2006-12291. 


\section{Introduction}

Deleted: -

Word count: 7120 words

Deleted:

The flexibility in the upstream side of supply chains has attracted the interest of many researchers in recent years. From an academic perspective, the study of flexibility across supply chains complements the vast research on manufacturing flexibility. However, Stevenson and Spring (2007), in an exhaustive literature review on supply chain flexibility, remarked the lack of empirical research on the subject, notably on assessment methodologies. From a practical viewpoint, many firms are increasingly relying on supply networks to assure a rapid response to the market. For example, the use of 'virtual integration' with suppliers and logistics providers is one of the methods that Dell uses to assure higher agility in the computer sector (Magretta 1998).

In this study, based on the definitions by Duclos et al. (2003) and Upton (1994), we consider supply flexibility as the ability of the purchasing function to respond in a timely and cost effective manner to changing requirements of purchased components, in terms of volume, mix and delivery date. Different management practices are applied to increase supply flexibility. For example: some firms emphasize supplier localization (e.g. high-fashion Italian firms prefer to maintain a network of domestic subcontractors (Jin 2004)). Other companies prioritise flexible supply contracts (Eppen and Iyer 1997). Alternatively, the use of information technology tools (e.g. EDI, e-marketplaces and supply chain planning software) is an option (Saeed et al. 2005).

Nonetheless, there are few empirical studies that compare the effectiveness (i.e. 'the capacity of producing a desired effect', according to the definition from the Merriam-Webster dictionary) of the different supply flexibility sources (e.g. Prater et al. 2001, Lee 2004). Indeed, Sawhney (2006) claims that 'opportunities exist for both theoretical and empirical researchers to examine the various management actions that promote both the acquisition of the dimensions of flexibility and the reduction of uncertainty in the value chain'. Moreover, most of the previous supply flexibility studies are theoretical or based on anecdotal evidence. Additionally, the literature on flexibility is generally limited to Operations Management (OM) issues and does not specifically address purchasing (Giunipero et al. 2005). Finally, there is a lack of studies analysing other variables (e.g. flexibility focus) that could affect the relationship between sourcing practices and supply flexibility. 
Based on these gaps found in the literature, the following research questions were proposed:

1. What is the effectiveness of the different supply flexibility sources?

2. Are there any variables that could moderate the relationship between supply flexibility sources and supply flexibility?

In the next section we review the literature on supply flexibility.

\section{Literature review}

\subsection{Supply flexibility}

There are some recent studies in the OM literature that focus on the flexibility in the upstream part of the supply chain. Zhang et al. (2002) drew from Porter (1985) to define purchasing flexibility as 'the ability of the organization to provide the variety of materials and supplies needed by manufacturing quickly and performance-effectively through cooperative relationships with suppliers.' However, it was a theoretical study, i.e. it lacked empirical validation of the constructs. The same applies to the study of Duclos et al. (2003) on supply flexibility, defined as 'the ability to meet the changing needs of customers, changing the supply of products, including mix, volume, product variations and new products'.

More recently, researchers followed an empirical approach to investigate flexibility in the upstream part of the supply chain. For example, Pujawan (2004) proposed a methodology to assess supply flexibility and provided a case study where this methodology was used. Swafford et al. (2006) were the first to develop and test a scale to measure sourcing flexibility, defined as 'the availability of a range of options and the ability of the purchasing process to effectively exploit them so as to respond to changing requirements related to the supply of purchased components'. This type of flexibility was divided into two dimensions: range (i.e. the number of different states that can be achieved with the existing resources) and adaptability (i.e. the ability to change from one state to another in a timely and cost effective manner).

Previous definitions present some common drawbacks. First, some flexibility items and sourcing practices overlap, fact that can represent an obstacle in studies aiming to analyse the effect of sourcing practices on supply flexibility. Second, they 
consider as unit of analysis all the components purchased by a firm, neglecting the deployment of different sourcing strategies for different products.

Based on these limitations, and considering the definitions of Duclos et al. (2003) and Upton (1994), in this study supply flexibility was defined as the ability of the purchasing function to respond in a timely and cost effective manner to changing requirements of purchased components, in terms of volume, mix and delivery date. The main difference with respect to previous studies lies in the assessment methodology. Flexibility was assessed at a specific component level (rather than at firm level). Moreover, special attention was dedicated to the design of the assessment items in order to avoid overlapping with sourcing practices.

In the next section, we review the sourcing practices that have been acknowledged to increase supply flexibility (i.e. supply flexibility sources).

\subsection{Sources of supply flexibility}

Jack and Raturi (2002) defined flexibility sources as 'specific actions to generate flexibility'. Accordingly, we define a supply flexibility source as a practice in the purchasing function that allows an increase in supply flexibility. In this section, we provide a literature review of the sources of supply flexibility. A schematic view of them is shown in Table 1.

\section{INSERT TABLE 1 HERE}

Multiple sourcing: Many authors (e.g. Quayle 1998, Zeng 2000, Minner 2003) have suggested the positive effect of multiple sourcing on supply flexibility. Networks of smaller contractors have been largely used in several sectors (e.g. fashion apparel) as a means of spreading the production risks, and increasing the responsiveness to sudden changes in demand.

Domestic sourcing: Many authors (e.g. Smith 1999, Christopher 2000, Stratton and Warburton 2003, Bruce et al. 2004) claim that the higher the demand volatility, the greater the inclination to buy from local suppliers. For example, Benetton insists on using local subcontractors in Italy rather than buying from low-wage countries, because it assures on-time delivery and immediate response to trends (Jin 2004). 
Supplier integration: Numerous studies suggest that integrative practices have a positive effect on supply flexibility (Das et al. 2006, Swafford et al. 2006). Furthermore, trust and collaborative efforts between buyers and suppliers (e.g. joint planning, cross-functional teams, establishing common goals) improve supply chain responsiveness to uncertain environments (Christopher 2000, Wei and Krajewski 2000).

Joint product development: The early involvement of suppliers in product development can be used to increase supplier responsiveness during the production phase (Lee 2004), a typical example being the substantial involvement of key suppliers in the development of automotive systems (Womack et al. 1990). Moreover, joint product development may increase parts commonality (i.e. the same component can be used in several products), which reduces the need of supply flexibility (Pujawan 2004).

Supplier selection: When the focus of a firm is to develop a market-responsive process, the supplier selection process should be based on flexibility, rather than cost (Fisher 1997, Giunipero et al. 2005). For example, Choi and Hartley (1996) found that the capability of suppliers to make volume changes is an important supplier selection criterion in the automotive industry.

Flexible contracts: The amount of flexibility to be specified in a contract is one of the most important decision functions in materials procurement (Van der Vaart et al. 1996). Indeed, Wei and Krajewski (2000) argue that quantity flexible contracts, in which buyer and supplier negotiate the amount of deviation of actual orders from the forecasts, are an efficient source of flexibility in the upstream part of the supply chain.

Long-term relationships: Long-term relationships with key suppliers are positively associated with supplier delivery synchronization (De Toni and Nassimbeni 1999). Similarly, the higher trust present in long-term relationships enables the supplier to develop a more buyer-focused operation, which may imply the delivery of batches of multiple sizes (Bruce et al. 2004), or fast adaptation of supplier schedules in order to expedite shipments (Van der Vaart and Van Donk 2004).

Third-party logistics providers: Supply flexibility also depends on the process integration with another key element in the supply chain: the inbound logistics provider (Lee 2004). Integration can include operational (e.g. shipping garments on hangers (Bruce et al. 2004)) or strategic agreements with the logistics provider (e.g. a supplier hub managed by a third-party logistics company (Lee 2002)).

Alternative modes of transportation: Having alternative inbound modes of transportation (e.g. maritime, aerial, rail, etc) is acknowledged as a source of supply 
flexibility (Pujawan 2004, Zhang et al. 2002). The varied operational features (i.e. intransit time, cost, capacity, frequency of delivery, etc) of the different transportation modes increase the range of options available to meet the changing customer needs (Zhang et al. 2002).

E-marketplaces: Saeed et al. (2005) and Swafford et al. (2006b) argue that the use of inter-organizational systems in supply chains can be divided into two categories: electronic integration and electronic brokerage. Electronic integration will be explained in the next paragraph, and electronic brokerage corresponds to the use of emarketplaces. Online searching for suppliers offers access to a larger number of potential suppliers (Peleg et al. 2002, Lee 2002), allowing the prompt scaling up and down of operations (Kaplan and Sawhney 2000).

Electronic integration: In this study, electronic integration is the use of information technology (IT) tools (e.g. Electronic Data Interchange (EDI), supply chain planning software, Internet, etc) to integrate with supply chain partners (Saeed et al. 2005). Many authors consider electronic integration with suppliers as an important source of responsiveness in the upstream side of the supply chain (Wei and Krajewski 2000, Stratton and Warburton 2003, Bruce et al. 2004).

Internal Integration: Stevens (1989) considered internal integration as a removal of the intra-organizational barriers between departments. This sort of integration (e.g. between Purchasing and Logistics) permits an increase in the responsiveness to changing materials requirements (Swafford et al. 2006, Narasimhan et al. 2006).

Inventory buffers: Buffer stocks of critical items are commonly used to hedge against uncertainty (Lee 2002, Fisher 1997). Some studies suggest that they can partly compensate a lack of supplier integration, specifically when there is high volume uncertainty and low mix uncertainty (Van Donk and Van der Vaart, 2005).

In this study, the moderating effect of flexibility focus on the effectiveness of the distinct supply flexibility sources is also analysed. In the next section, we revise briefly some studies concerning flexibility focus.

\subsection{Flexibility focus}

The deployment of flexibility sources depends on the firm strategy and, more specifically, on its flexibility focus. Some empirical studies on flexibility have proposed 
measures of flexibility focus: 'managerial emphasis on flexibility' (Upton 1997) and 'flexibility importance' (Vickery et al. 1999), both based on perceptual assessment. Similarly, Krause et al. (2001) proposed a 'flexibility' factor, which measured the degree of importance of flexibility in the supplier selection procedure.

\section{Model development}

The objective of this paper is to analyse the effectiveness of several sourcing practices concerning the achievement of supply flexibility. Figure 1 depicts the research framework of this study.

\section{INSERT FIGURE 1 HERE}

In order to assure research generalizability, it is important to consider some control variables, the first one being flexibility focus. Most of the sourcing practices considered in this study can be employed to obtain goals different from flexibility (e.g. e-marketplaces may be introduced motivated by cost reduction, rather than flexibility increase). Therefore, it is important to add to the regression model a control variable in order to assure that the effects of the sourcing practices on flexibility are independent of the flexibility focus of the firm. Second, firm revenue may impact the level of utilization of each sourcing practice (e.g. bigger firms may have more resources to implement EDI than smaller ones). We observe that, in the OM literature, firm size is usually measured using either the number of employees, or the firm revenue. In our study, we used revenue, as the level of financial resources available to invest in many of the sourcing practices considered (e.g. EDI, e-marketplaces, 3PL, etc) may be determined by this figure (revenue) rather than by the number of employees. Firm revenue has also been used as a control variable in similar studies (e.g. Chen and Paulraj 2004, Narasimhan et al. 2006, Swafford et al. 2006). Thus, two control variables were added to the model: flexibility focus and revenue.

In the next section we explain the methodology used to design the questionnaire and to collect the data. 


\section{Methodology}

\subsection{The instrument}

In order to assure content validity, questionnaire items were based on previous studies (see Appendix) and pre-tests with purchasing managers and academics were used to guarantee a perfect understanding of the questions. Based on the pre-tests, the final version of the questionnaire incorporated some minor changes to improve the readability and clarity of the survey items.

\subsection{Sampling}

The sample consisted of members of the Spanish Association of Purchasing Managers (AERCE). All 1504 members of AERCE were asked to participate in the study, receiving an electronic message with a link to the web page of the survey. Nonrespondents received a second message, two weeks after the first one. A total of 100 answers were received. In order to show more precisely the relationship between sourcing practices and supply flexibility, 'not flexibility-focused' firms (i.e. 'flexibility focus' less or equal than five) were excluded from the study. After dropping the cases with missing data or not flexibility-focused firms, the total sample size was reduced to 77 firms, which means a response rate of $5.10 \%$. This slightly low response rate should be analysed in the context of other web-based surveys. Actually, studies suggest that the response rate in online surveys is lower than in mail questionnaires, being as low as $7 \%$ in some cases (Braunsberger et al. 2007). In addition, it is important to consider the length and broad nature of the questionnaire, as well as the confidential nature of the information requested. Moreover, a demonstrated lack of response bias is considerably more important than a high response rate (Babbie 1990). For this reason, non-response bias was checked, by comparing early and late respondents. In particular, the first 30 received surveys and the last 30 received surveys were compared, using 10 randomly selected variables. Results suggested no significant difference between both groups, indicating that non-response bias is not a cause of concern (Hair et al. 1998), and that the sample is adequate to make inferences about the whole population. Therefore, we 
may assume that the 77 usable responses provide enough data to attain the research objectives.

The industry and size distribution of the sample can be appreciated in Table 2.

\section{INSERT TABLE 2 HERE}

\section{Data analysis and discussion}

\subsection{Factor analysis}

Exploratory factor analysis with varimax rotation was conducted in order to explore the underlying supply flexibility dimensions. In the interest of convergent and discriminant validity, we only considered items that had a factor loading higher than 0.50 and did not have a loading in excess of 0.40 on a second factor (Bagozzi and Yi 1988). Cronbach's alpha was used to evaluate reliability (i.e. how well a set of items measures a single one-dimensional latent construct values). In general, reliability coefficients of 0.70 are considered satisfactory, but some researchers consider 0.60 as a practical cut-off (Swafford et al. 2006, Chen and Paulraj 2004).

The final factor loadings of the supply flexibility retained items, as well as their underlying factors, can be appreciated in Table 3. The Kaiser-Meyer-Olkin test of sampling adequacy $(\mathrm{KMO}=0.531)$ and the Bartlett's test of sphericity (significance $=$ 0.000 ) were within the generally accepted limits, suggesting that factor analysis could be applied (Malhotra 1996). Cronbach's alpha was at least 0.608 for all dimensions of supply flexibility (see Table 3 ), indicating that construct reliabilities were adequate.

\section{INSERT TABLE 3}

Results of the factor analysis suggested the existence of three underlying dimensions of supply flexibility: delivery policy (FLEX1 and FLEX2), supplier responsiveness (FLEX3 and FLEX4) and adaptability (FLEX6, FLEX7 and FLEX9). The delivery policy dimension measures the capacity of varying delivery lot sizes and frequencies. Lot size and frequency are variables usually associated. For example, JIT studies often support the combination of small supplier lot sizes and frequent deliveries 
(e.g. Womack et al. 1990, Ponce and Prida 2004). Supplier responsiveness is the ability of influencing supplier short-term capacity and delivery lead-time. Similarly, Choi and Krause (2006) define it as 'the degree of promptness and accuracy of the supplier's response to the focal company's request for new requirements'. And, adaptability is the time or cost necessary to change the specification of components, implement supplier engineering change orders or alter short-term capacity of suppliers. This coincides with the 'adaptability' dimension of sourcing flexibility (i.e. the ease with which the firm can exercise its procurement options (Swafford et al. 2006)).

These results differ slightly from previous studies (e.g. Swafford et al. 2006). The main difference is the partitioning of the 'range' dimension of supply flexibility (Swafford et al. 2006) into two dimensions (i.e. 'supplier responsiveness' and 'delivery policy'). The 'adaptability' dimension identified in our paper is analogous to previous studies (Swafford et al. 2006, Swafford et al. 2006b). Next, the different dimensions of supply flexibility are examined individually.

\subsection{Regression analysis}

According to the research framework presented in section three, we conducted a regression analysis using the flexibility sources as independent variables. Composite factor scores of each of the three dimensions of supply flexibility derived in the factor analysis (supplier responsiveness, delivery policy and adaptability) were used as dependent variables. The research model is depicted in Figure 2.

\section{INSERT FIGURE 2 HERE}

The underlying assumptions of regression analysis - normality, linearity and homoscedasticity were examined through the analysis of the normal probability plot of residuals and the plots of the residuals against the predicted values. This analysis suggested that there were no violations of the regression assumptions.

Multicollinearity can also be a problem in multiple regression. Thus, before running the multiple regression, we first checked the bivariate collinearity using the correlation matrix of the independent variables. The correlation matrix analysis suggested that there are some potential sources of bivariate collinearity among the flexibility sources SRC3 (supplier integration), SRC4 (joint product development), and 
SRC11 (internal integration). There was a moderate correlation between SRC3 and SRC4 $(r=0.656)$, between SRC11 and SRC4 $(r=0.438)$ and between SRC3 and SRC11 $(\mathrm{r}=0.434)$. A content analysis also suggested some redundancy between variables SRC3 and SRC4. To prevent problems, the SRC4 variable was dropped from the regression analysis. We maintained SRC3 (supplier integration) because this variable was more general and encompassed much of SRC4 (joint product development). SCR11 was kept because the distinction between internal and external integration is conceptually important for the study.

In order to check for multivariate collinearity, we performed a preliminary analysis of the regression of each independent variable on the remaining independent variables. The variance inflation factors (VIF) scores obtained this way were smaller than the cut-off of 10 (Mason and Perrault 1991), suggesting no multicollinearity problems. However, an additional analysis of the condition indexes revealed that there were two values above 15, suggesting moderate multicollinearity (Belsley et al. 1980).

To minimize problems generated by multicollinearity, stepwise regression was applied to select the independent variables that would be included in the model, a procedure which has been largely used in OM studies (e.g. Johnson 2002, GonzalezBenito et al. 2003, Flynn and Saladin 2006). Later, the model was refined adding some control variables (revenue and flexibility focus). This regression procedure was repeated for each dependent variable (supplier responsiveness, delivery policy and adaptability). In the next sections, the results for each of the dependent variables (supplier responsiveness, delivery policy and adaptability) are analysed.

5.2.1 Supplier responsiveness. As previously explained, stepwise regression was applied to select the independent variables (sources) that affect supplier responsiveness. The model that best explained the observed variance in the supplier responsiveness construct had two independent variables: SRC2 (domestic sourcing) and SRC11 (internal integration). Therefore, as a first step we evaluated the model including these variables. In a second step we added the control variables ('revenue' and 'flexibility focus'), and in a third step we added the interaction effects. Schematically, we evaluated the following models:

$$
\begin{aligned}
& \mathrm{SR}=\beta_{0}+\beta_{1} * \mathrm{SRC} 2+\beta_{2} * \mathrm{SRC} 11+\varepsilon \\
& \mathrm{SR}=\beta_{0}+\beta_{1} * \mathrm{SRC} 2+\beta_{2} * \mathrm{SRC} 11+\beta_{3} * \mathrm{REV}+\beta_{4} * \mathrm{IMP}+\varepsilon
\end{aligned}
$$




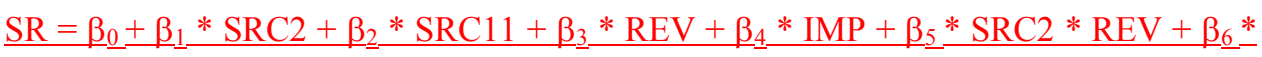

$\underline{\mathrm{SRC} 2 * \mathrm{IMP}+\underline{\beta}_{7}} \underline{\underline{\mathrm{SRC}} 11 * \mathrm{REV}+\beta 8 * \mathrm{SRC} 11 * \mathrm{IMP}+\varepsilon}$

where SR is 'supplier responsiveness'; SRC2 is 'domestic sourcing'; SRC11 is 'internal integration'; REV is 'firm revenue'; IMP is 'flexibility focus' and $\varepsilon$ is the error term of the regression model.

The results can be appreciated in Table 4. After controlling for revenue and flexibility focus the model is still significant, as well as the regression coefficients. Results suggest that domestic sourcing (standardized beta $=0.290, \mathrm{p}=0.011$ ) and internal integration (standardized beta $=0.245, \mathrm{p}=0.031$ ) are positively associated to supplier responsiveness. As far as the control variables are concerned, 'revenue' and 'flexibility focus' have no significant effect on the dependent variable. After adding the interaction terms (SRC2*IMP, SRC2*REV, SRC11*IMP and SRC11*REV), the model is significant $(p=0.009)$. However, none of the regression coefficients are statistically significant. Therefore, the model does not suggest a moderator effect of 'flexibility focus' or 'revenue' on the relationship between the flexibility sources and supplier responsiveness.

\section{INSERT TABLE 4 HERE}

Potential outliers and influential cases were examined. Univariate outliers were verified using the cutoff of three standard deviations from the mean. Multivariate outliers were checked using two cut-offs: an absolute (Cook's D should be less than 1), and a size-adjusted (Cook's D should be less than 4/n (Hamilton 1992)). The absolute cut-off revealed no influential case. The size-adjusted (Cook's D > 0.052) cut-off suggested seven influential cases. We ran the stepwise regression without those cases, and then the results suggested that the variable SRC11 (internal integration) was replaced by SRC3 (supplier integration). This can be explained by the moderate correlation $(\mathrm{r}=0.434, \mathrm{p}<0.01)$ between both variables. Thus, generalizability of results should be looked at carefully, and further studies should investigate the separate effect of each variable on supply flexibility.

Interestingly, SRC2 (domestic sourcing), SRC3 (supplier integration) and SRC11 (internal integration) can be viewed as 'integration' variables (if domestic sourcing is considered as a sort of 'physical integration'), which suggests a positive 
relationship between supply chain integration and supplier responsiveness. This result contributes to the increasing debate about the relationship between integration and flexibility. In fact, this relationship is somewhat controversial. Although some researchers claim that integration increases supplier responsiveness (e.g. Choi and Krause 2006, Swafford et al. 2006), Das et al. (2006) have suggested that integration actually slows an organization's response to change, by creating interdependencies and increased decision times (e.g. when firms implement cross-functional teams).

This study adds to this debate by analysing individually the effect of integration practices on supplier responsiveness, controlling for flexibility focus and firm size. Although the results suggest that this relationship is positive, further research is still needed. For example, future studies should take into consideration a wider array of integration practices (e.g. vendor-managed inventories) and context variables (e.g. environmental uncertainty).

5.2.2 Delivery Policy. Next, we describe the regression of the second supply flexibility dimension (delivery policy) on the flexibility sources. The model that best explains the observed variance in the delivery policy dimension has only one independent variable: SRC5 (supplier selection). As a first step we evaluated the model including this independent variable. In a second step we added the control variables ('revenue' and

Deleted: and in a 'flexibility focus'), and in a third step we added the interaction effects. The regression equations evaluated are:

$\mathrm{DP}=\beta_{0}+\beta_{1} * \mathrm{SRC} 5+\varepsilon$

$\mathrm{DP}=\beta_{0}+\beta_{1} * \operatorname{SRC} 5+\beta_{2} * \mathrm{REV}+\beta_{3} * \mathrm{IMP}+\varepsilon$

$\underline{\mathrm{DP}}=\underline{\beta}_{0}+\underline{\beta}_{1} * \mathrm{SRC} 5+\underline{\beta}_{2} * \mathrm{REV}+\beta_{3} * \mathrm{IMP}+\beta_{4} * \mathrm{SRC} 5 * \mathrm{REV}+\underline{\beta}_{5} * \mathrm{SRC} 5 * \mathrm{IMP}+$ $\underline{\varepsilon}$

where DP is 'delivery policy'; SRC5 is 'supplier selection'; REV is 'firm revenue'; IMP is 'flexibility focus' and $\varepsilon$ is the error term of the regression model.

Results suggest that, controlling for firm size and flexibility focus, the model is still significant ( $p$-value $=0.047$ ), as well as the regression coefficient ( $p$-value $=0.016$ ). As far as the control variables are concerned, 'revenue' and 'flexibility focus' have no significant effect on the dependent variable. After adding the interaction terms (SRC5*IMP and SRC5*REV), the model is not significant. Therefore, the model does 
not suggest a moderator effect of 'flexibility focus' or 'revenue' on the relationship between the flexibility sources and delivery policy.

The results can be seen in Table 5 .

\section{INSERT TABLE 5 HERE}

This positive relationship between supplier selection and having a flexible delivery policy (standardized beta $=0.283, \mathrm{p}=0.016$ ) concurs with previous studies (Pujawan 2004, Swafford et al. 2006b). By carefully selecting its suppliers, a firm can assure that they possess crucial capabilities, like producing in small batches or having flexible delivery channels (i.e. capable of accommodating a significant range of lot sizes and delivery frequencies).

This result corroborates the idea that price should not be the sole criterion to select suppliers (Nassimbeni et al. 2003) and that a flexible delivery policy could compensate higher prices of material (Giunipero et al. 2005).

5.2.3 Adaptability. Next, we describe the regression of the 'adaptability' dimension of supply flexibility on the flexibility sources. The model that best explained the observed variance in the adaptability dimension had three independent variables: SRC8 (logistics provider integration), SRC9 (alternative transportation modes) and SRC12 (electronic integration). As a first step we evaluated the model including these independent variables. In a second step we added the control variables ('revenue' and 'flexibility focus'), and in a third step we added the interaction effects. The regression equations evaluated are:

$\mathrm{A}=\beta_{0}+\beta_{1} * \mathrm{SRC} 8+\beta_{2} * \mathrm{SRC} 9+\beta_{3} * \mathrm{SRC} 12+\varepsilon$

$\mathrm{A}=\beta_{0}+\beta_{1} * \mathrm{SRC} 8+\beta_{2} * \mathrm{SRC} 9+\beta_{3} * \mathrm{SRC} 12+\beta_{4} * \mathrm{REV}+\beta_{5} * \mathrm{IMP}+\varepsilon$

$\underline{\mathrm{A}=\beta_{0}}+\underline{\beta}_{1} * \mathrm{SRC} 8+\underline{\beta}_{2} * \mathrm{SRC} 9+\underline{\beta}_{3} * \mathrm{SRC} 12+\underline{\beta}_{4} * \mathrm{REV}+\underline{\beta}_{5} * \mathrm{IMP}+\underline{\beta}_{6} * \mathrm{SRC} 8 *$ $\underline{\mathrm{REV}}+\underline{\beta}_{7} * \mathrm{SRC} 8 * \mathrm{IMP}+\underline{\beta}_{8} * \mathrm{SRC} 9 * \mathrm{REV}+\underline{\beta}_{9} * \mathrm{SRC} 9 * \mathrm{IMP}+\underline{\beta}_{10} * \mathrm{SRC1} *$ $\underline{\mathrm{REV}+\beta_{11}} \underline{\underline{\mathrm{SRC}} 12 * \mathrm{IMP}+\varepsilon}$

where A is 'adaptability'; SRC8 is 'logistics provider integration'; SRC9 is 'alternative transportation modes'; SRC12 is 'electronic integration'; REV is 'firm revenue'; IMP is 'flexibility focus' and $\varepsilon$ is the error term of the regression model.

Results suggest that, controlling for revenue and flexibility focus, the model is still significant ( $p$-value $=0.006$ ), as well as the regression coefficients for SRC8 $(p=$ 
0.033), SRC9 $(\mathrm{p}=0.035)$ and SRC12 $(\mathrm{p}=0.003)$. Regarding the control variables, 'revenue' and 'flexibility focus' have no significant effect on the dependent variable. After including the interaction terms (SRC8*IMP, SRC8*REV, SRC9*IMP, SRC9*REV, SRC12*IMP, SRC12*REV), the model is not significant. Thus, the model does not support the hypothesized moderator effect of 'flexibility focus' or 'revenue' on the relationship between the flexibility sources and adaptability.

Results are displayed in Table 6.

\section{INSERT TABLE 6 HERE}

The positive relationship between electronic integration and adaptability (standardized beta $=0.348, \mathrm{p}=0.003$ ) is somewhat different from the results from Swafford et al. (2006), who did not find a significant correlation between procurement IT capabilities and adaptability. Nevertheless, results coincide with most of the studies on supply chain agility, which support the effect of procurement IT on supply chain responsiveness (Christopher 2000, Bruce et al. 2004, Chung et al. 2004, Saeed et al. 2005). Further research with a broader sample of firms and industrial sectors should be conducted to confirm these results and to contrast them with previous studies.

Another finding was the positive relationship between the use of alternative transportation modes and adaptability (standardized beta $=0.244, p=0.035$ ). This result coincides with the notion that customized logistics networks should be tailored to each customer segment (Lummus and Vokurka 1999).

Interestingly, a negative association between logistics provider integration and adaptability (standardized beta $=-0.259, \mathrm{p}=0.033$ ) was found. This result departs from previous studies, which associate third-party logistics provider integration with flexibility (Anderson et al. 1997). A plausible reason for such a finding could be due to potential negative effects of integration on flexibility. Das et al. (2006) argue that some causes for this phenomenon could be: excessive caution among inexperienced team members, need for consultations in decision-making, communication delays and coordination needs. Anyway, the discrepancy of results suggests the need for further studies and replication of analysis using a broader sample of firms. Further research should also incorporate other variables (such as length of relationship, type of product/service bought, etc) that could explain why integration with the supplier increases supply flexibility while integration with the logistics provider does not. 


\section{Conclusion}

This study adds to previous literature on supply flexibility by suggesting that flexibility sources (e.g. supplier integration, domestic sourcing, flexible contracts, etc) act differently over each supply flexibility dimension (i.e. supplier responsiveness, delivery policy and adaptability). With respect to the first research question proposed in the introduction (i.e. what is the effectiveness of the different supply flexibility sources?), we conclude that this depends on the dimension of supply flexibility considered: when we consider supplier responsiveness, domestic sourcing and internal integration are more effective in achieving flexibility. When the dimension considered is delivery policy, supplier selection is the most significant source. Finally, when adaptability is considered, electronic integration and alternative modes of transportation are more strongly associated to flexibility.

With respect to the second research question (i.e. are there any variables that could moderate the relationship between supply flexibility sources and supply flexibility?), our results do not suggest a moderator effect considering any of the variables proposed (flexibility focus and revenue). Nevertheless, we believe that this remains a fertile stream of research. For instance, further studies could investigate the influence of different operating environments (e.g. product variety, product life cycle, type of operations (i.e. make-to-stock or make-to order)) on the relationship between flexibility sources and supply flexibility.

This study has several research implications. First, the relationship between Deleted: 9 flexibility sources and the supply flexibility is a complex issue that deserves a multidimensional analysis. Second, this study provides researchers with a framework that can be used to investigate quantitatively the effects of managerial practices on supply flexibility. Lastly, the focus on flexibility adds to the integration literature, which has been mostly restricted to the strategic objective of reducing costs or lead-times.

This study has some important managerial implications. First, this research supports the notion that integration affects positively supplier responsiveness. More specifically, firms that adopt supplier collaboration (e.g. collaborative planning, sharing of information, joint establishment of goals), integrate purchasing with other internal functions (e.g. production, logistics) and adopt domestic sourcing have higher supplier 
responsiveness. Second, there is a positive relationship between flexibility-based supplier selection and flexible supplier delivery policies. Therefore, firms seeking a flexible supplier delivery policy (i.e. adjustable lot sizes and delivery frequencies) should include some flexibility verifications (e.g. excess capacity and responsiveness) in the supplier selection procedures. Third, electronic integration has a positive effect on adaptability. In other words, by investing in procurement IT (e.g. EDI, supply chain planning software, etc), firms can increase their capacity of adapting quickly to changes in demand patterns (e.g. volume, mix and delivery fluctuations). Finally, these effects are independent of firm revenue or flexibility focus.

This study has several limitations that future researchers should consider. First, the sample was drawn from a single country, thus in future studies a more geographically diversified sample of firms should be considered. Second, although the statistical procedures suggest sufficient validity, the sample size should be larger in further studies, to increase the generalizability of the results. Third, the use of singleinformants raises the issue of a potential informant bias. Accordingly, further studies considering multiple informants would lead to a more complete understanding of the approaches used by firms to increase supply flexibility. Finally, cross-sectional studies may assume causal relationships among variables that may not correspond to reality. In further research, causal relationships should be confirmed using longitudinal studies.

As a general conclusion, this study provided important clues for better understanding the effects of sourcing practices on supply flexibility. Nevertheless, considerable research is necessary before arriving at a general, empirical understanding of the actions managers should take to improve the various dimensions of supply flexibility.

\section{References}

Anderson, D.L., Britt, F.E. and Favre, D.J., The seven principles of supply chain management. Supply Chain Management Review, 1997, 1(1), 1-12.

Babbie, E., Survey Research Methods, 1990 (Wadsworth Publishing Company: Belmont, CA).

Bagozzi, R.P. and Yi, Y., On the evaluation of structural equation models. Journal of Academy of Marketing Science, 1988, 16(1), 74-94. 
Belsley, D.A., Kuh, E. and Welsh, R.E., Regression Diagnostics - Identifying Influential Data and Sources of Collinearity, 1980 (John Wiley \& Sons: New York).

Braunsberger, K., Wybenga, H. and Gates, R., A comparison of reliability between telephone and web-based surveys, Journal of Business Research, 2007 (forthcoming).

Bruce, M., Daly, L. and Towers, N., Lean or agile: a solution for supply chain management in the textiles and clothing industry?, International Journal of Operations and Production Management, 2004, 24(2), 151-170.

Chen, I.J. and Paulraj, A., Towards a theory of supply chain management: The constructs and measurements, Journal of Operations Management, 2004, 22(2), $119-150$.

Choi, T. and Hartley, J., An exploration of supplier-selection practices across the supply chain. Journal of Operations Management, 1996, 14(4), 333-343.

Christopher, M., The agile supply chain: Competing in volatile markets, Industrial Marketing Management, 2000, 29(1), 37-44.

Chung, W.W.C., Yam, A.Y.K. and Chan, M.F.S., Networked enterprise: A new business model for global sourcing. International Journal of Production Economics, 2004, 87(3), 267-280.

Das, A., Narasimhan, R. and Talluri, S., Supplier integration - Finding an optimal configuration. Journal of Operations Management, 2006, 24(5), 563-582.

De Toni, A. and Nassimbeni, G., Buyer-supplier operational practices, sourcing policies and plant performances: results of an empirical research. International Journal of Production Research, 1999, 37(3), 597-619.

Duclos, L.K., Vokurka, R.J. and Lummus, R.R., A conceptual model of supply chain flexibility. Industrial Management \& Data Systems, 2003, 103(6), 446-456.

Eppen, G.D and Iyer, A.V., Backup agreements in fashion buying: The value of upstream flexibility. Management Science, 1997, 43(11), 1469-1484.

Fisher, M.L., What is the right supply chain for your product?. Harvard Business Review, 1997, 75 (2), 105-116.

Flynn, B.B. and Saladyn, B., Relevance of Baldridge constructs in an international context: A study of national culture , Journal of Operations Management, 2005, 24(5), 583-683. 
Giunipero, L.C., Denslow, D. and Eltantawy, R., Purchasing/supply chain management flexibility: Moving to an entrepreneurial skill set, Industrial Marketing Management, 2005, 34(6), 602-613.

Gonzalez-Benito, J., Martínez-Lorente, A.R. and Dale, B.G., A study of the purchasing management system with respect to total quality management. Industrial Marketing Management, 2003, 32(6), 443-454.

Hair, J.F., Tatham, R.L., Anderson, R.E. and Black, W., Multivariate Data Analysis, 1998 (Prentice-Hall: New York).

Hamilton, L.C., Regression with graphics: A second course in applied statistics, 1992 (Pacific Grove: California).

Jin, B., Achieving an optimal global versus domestic sourcing balance under demand uncertainty. International Journal of Operations and Production Management, 2004, 24(12), 1292-1305.

Johnson, D., Empirical study of second-tier automotive suppliers achieving QS-9000. International Journal of Operations and Production Management, 2002, 22(8), 902-928.

Kaplan, S. and Sawhney, M., E-hubs: The new B2B marketplaces. Harvard Business Review, 2000, 78(3), 97-102.

Krause, D.R., Pagell, M. and Curkovic, S., Toward a measure of competitive priorities for purchasing. Journal of Operations Management, 2001, 19 (4), 497-512.

Lee, H.L., Aligning supply chain strategies with product uncertainties. California Management Review, 2002, 44(3), 105-119.

Lee, H.L., The triple-A supply chain. Harvard Business Review, 2004, 82(10), 102-112.

Lummus, R.R. and Vokurka, R.J., Defining supply chain management: a historical perspective and practical guidelines. Industrial Management and Data Systems, 1999, 99(1), 11-17.

Magretta, J., The power of virtual integration: An interview with Dell Computer's Michael Dell. Harvard Business Review, 1998, 76(2), 72-84.

Malhotra, N.K., Marketing Research: An applied orientation, 1996 (Englewood Cliffs, Prentice-Hall: New Jersey).

Mason, C.H. and Perreault, W.D., Collinearity, power and interpretation of multiple regression analysis. Journal of Marketing Research, 1991, 28(3), 268-280.

Minner, S., Multiple-supplier inventory models in supply chain management: A review. International Journal of Production Economics, 2003, 81-82(11), 265-279. 
Narasimhan, R., Swink, M. and Kim, S.W., Disentangling leanness and agility: An empirical investigation. Journal of Operations Management, 2006, 24(5), 440457.

Nassimbeni, G., Local manufacturing systems and global economy: Are they compatible? The case of the Italian eyewear district. Journal of Operations Management, 2003, 21(2), 151-171.

Peleg, B., Lee, H.L. and Haussman, W.H., Short-term e-procurement strategies versus long-term contracts. Production and Operations Management, 2002, 11(4), 458479.

Ponce, E. and Prida, B., La logística de aprovisionamientos para la integración de la cadena de suministros, 2004 (Pearson Educación: Madrid).

Porter, M.E., Competitive advantage, 1985 (Free Press: New York)

Prater, E., Biehl and M., Smith, M.A.), International supply chain agility: Tradeoffs between flexibility and uncertainty. International Journal of Operations and Production Management, 2001, 21(5/6), 823-839.

Pujawan, N., Assessing supply chain flexibility: a conceptual framework and a case study. International Journal of Integrated Supply Management, 2004, 1(1), 7997.

Quayle, M., Industrial procurement: Factors affecting sourcing decisions. European Journal of Purchasing and Supply Management, 1998, 4(1), 199-205.

Saeed, K.A., Malhotra, M.K. and Grover, V., Examining the impact of interorganizational systems on process efficiency and sourcing leverage in buyer-supplier dyads. Decision Sciences, 2005, 36(3), 365-396.

Sawhney, R., Interplay between uncertainty and flexibility across the value-chain: Towards a transformation model of manufacturing flexibility. Journal of Operations Management, 2006, 24(5), 476-493.

Smith, J.M., Item selection for global purchasing. European Journal of Purchasing and Supply Management, 1999, 5(1), 117-127.

Stevens, G.C., Integrating the supply chain. International Journal of Physical Distribution and Materials Management, 1989, 19(8), 3-8.

Stevenson, M. and Spring, M., Flexibility from a supply chain perspective: definition and review. International Journal of Operations and Production Management, 2007, 27(7), 685-713. 
Stratton, R. and Warburton, R.D.H., The strategic integration of agile and lean supply. International Journal of Production Economics, 2003, 85(2), 183-198.

Swafford, P., Ghosh, S. and Murthy, N., The antecedents of supply chain agility of a firm: Scale development and model testing. Journal of Operations Management, 2006, 24(2), 170-188.

Swafford, P., Ghosh, S. and Murthy, N., A framework for assessing value chain agility. International Journal of Operations and Production Management, 2006, 26(2), 118-140.

Upton, D.M., The management of manufacturing flexibility. California Management Review, 1994, 36(2), 72-89.

Upton, D.M., Process range in manufacturing. Management Science, 1997, 43(8), 10791092.

Van Der Vaart, J.T., De Vries, J. and Wijngaard, J., Complexity and uncertainty of materials procurement in assembly situations. International Journal of Production Economics, 1996, 46-47, 137-152.

Van der Vaart, T. and Van Donk, D.P., Buyer focus: Evaluation of a new concept for supply chain integration. International Journal of Production Economics, 2004, 92(1), 21-30.

Van Donk, D.P. and Van der Vaart, T., A case of shared resources, uncertainty and supply chain integration in the process industry. International Journal of Production Economics, 2005, 96(1), 97-108.

Vickery, S., Calantone, R. and Dröge, C., Supply chain flexibility: an empirical study. The Journal of Supply Chain Management, 1999, 35(1), 16-24.

Wei, J. and Krajewski, L., A model for comparing supply chain schedule integration approaches. International Journal of Production Research, 2000, 38(9), 20992123.

Womack, J.P., Jones and D.T., Roos, D., The Machine that Changed the World, 1990 (Macmillan Publishing Company: New York, NY).

Zeng, A.Z., A synthetic study of sourcing strategies. Industrial Management \& Data Systems, 2000, 100(5), 219-226.

Zhang, Q., Vonderembse, M.A. and Lim, J., Value chain flexibility: a dichotomy of competence and capability. International Journal of Production Research, 2002, 40(3), 561-583. 


\section{Tables}

Table 1 . Sources of supply flexibility.

\begin{tabular}{|c|c|}
\hline Source & References \\
\hline Multiple sourcing & $\begin{array}{l}\text { Quayle 1998, Zeng 2000, Minner 2003, Stratton and } \\
\text { Warburton } 2003\end{array}$ \\
\hline Domestic sourcing & $\begin{array}{l}\text { Smith 1999, Christopher 2000, Stratton and Warburton } \\
\text { 2003, Bruce et al. 2004, Jin } 2004\end{array}$ \\
\hline Supplier integration & $\begin{array}{l}\text { Wei and Krajewski 2000, Christopher 2000, Das et al. } \\
\text { 2006, Swafford et al. } 2006\end{array}$ \\
\hline Joint product development with suppliers & Womack et al. 1990, Lee 2004 \\
\hline Supplier selection & Fisher 1997, Nassimbeni 2003, Swafford et al. 2006 \\
\hline Flexible supply contracts & Eppen and Iyer 1997, Wei and Krajewski 2000 \\
\hline Long-term relationships with suppliers & De Toni and Nassimbeni 1999, Bruce et al. 2004 \\
\hline Third-party logistics providers & Lee 2002, Lee 2004, Bruce et al. 2004 \\
\hline Alternative transportation modes & Zhang et al. 2002, Pujawan 2004 \\
\hline E-marketplaces & $\begin{array}{l}\text { Kaplan and Sawhney 2000, Peleg et al. 2002, Lee 2002, } \\
\text { Saeed et al. } 2005\end{array}$ \\
\hline Internal integration & $\begin{array}{l}\text { Swafford et al. 2006, Narasimhan et al. 2006, Das et al. } \\
2006\end{array}$ \\
\hline Electronic integration & $\begin{array}{l}\text { Wei and Krajewski 2000, Stratton and Warburton 2003, } \\
\text { Bruce et al. 2004, Chung et al. 2004, Saeed et al. } 2005\end{array}$ \\
\hline Inventory buffers & $\begin{array}{l}\text { Fisher 1997, Wei and Krajewski 2000, Lee 2002, Stratton } \\
\text { and Warburton } 2003\end{array}$ \\
\hline
\end{tabular}

Table 2. Industry mix and sales.

\begin{tabular}{|c|c|c|c|}
\hline Industrial sector & $\%$ & Revenue (million euros) & $\%$ \\
\hline Electronics & 13.0 & $<1$ & 1.3 \\
\hline Machinery & 19.5 & $1-49$ & 41.6 \\
\hline Industrial & 2.6 & $50-99$ & 23.4 \\
\hline Basic & 31.2 & $100-499$ & 24.7 \\
\hline $\begin{array}{l}\text { Consumer packaged } \\
\text { goods }\end{array}$ & 15.6 & $>500$ & 9.1 \\
\hline Not informed & 18.2 & Total & 100 \\
\hline
\end{tabular}


Table 3. Supply flexibility: reliability and convergent validity.

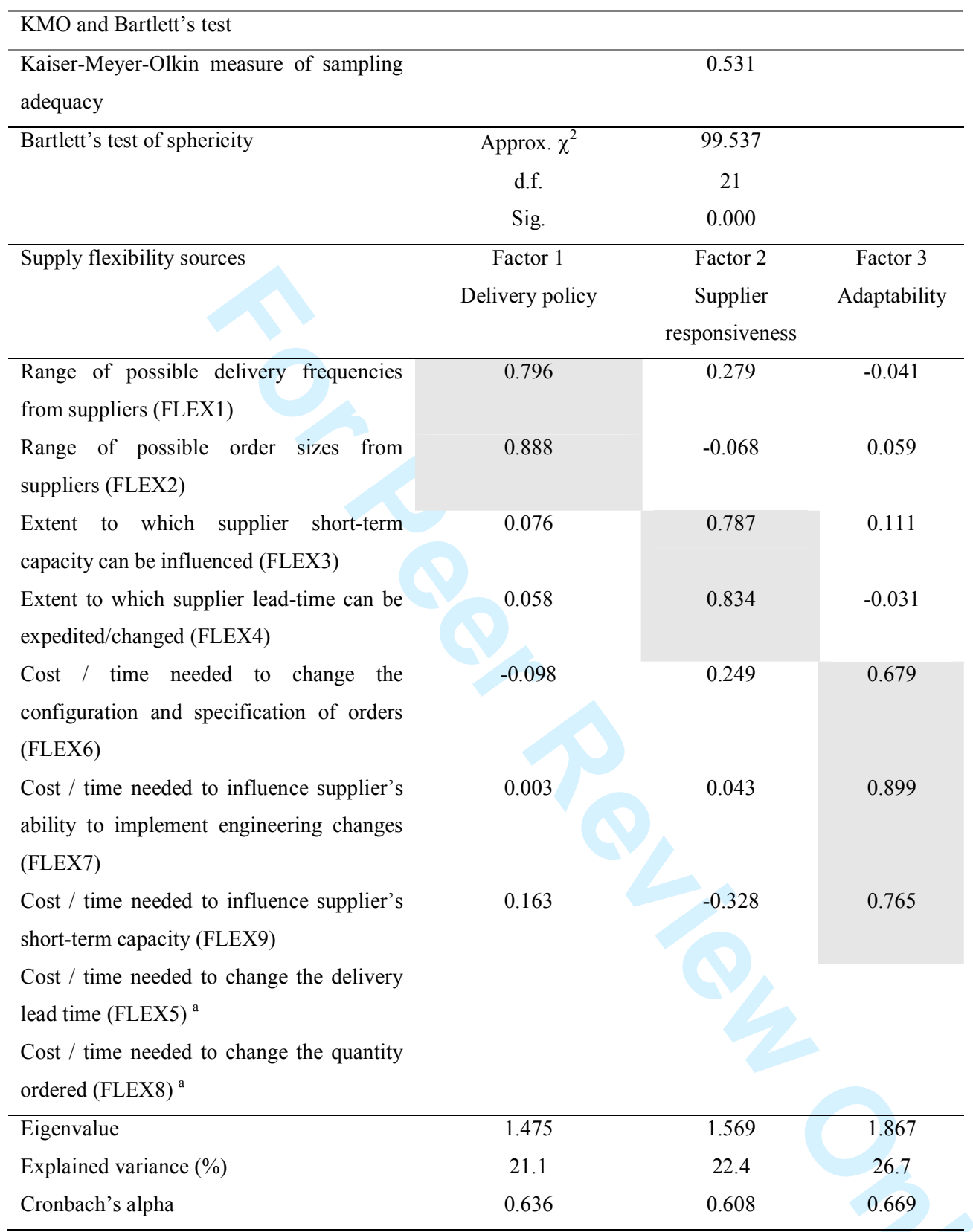

Extraction method: Principal Component Analysis. Rotation Method: Varimax with Kaiser Normalization.

${ }^{\mathrm{a}}$ Items dropped (for having factor loadings of less than 0.5 or a loading in excess of 0.4 on a second factor) 
Table 4. Regression results (supplier responsiveness).

\begin{tabular}{|c|c|c|c|c|c|c|c|}
\hline Model & Adjusted $\mathrm{R}^{2}$ & $\underline{\text { F-value }}$ & $\underline{\text { Significance F }}$ & $\underline{\text { Variables }}$ & $\underline{\text { Standardized } \beta}$ & $\underline{\text { T-value }}$ & Significance \\
\hline \multirow[t]{3}{*}{$\underline{\text { Step } 1}$} & $\underline{0.167}$ & $\underline{8.629}$ & $\underline{0.000}$ & Constant & & $\underline{3.921}$ & $\underline{0.000}$ \\
\hline & & & & $\underline{\mathrm{SRC} 2}$ & $\underline{0.300}$ & $\underline{2.740}$ & $\underline{0.008}$ \\
\hline & & & & $\underline{\mathrm{SRC} 11}$ & $\underline{0.239}$ & $\underline{2.182}$ & $\underline{0.032}$ \\
\hline \multirow[t]{5}{*}{$\underline{\text { Step } 2}$} & $\underline{0.155}$ & $\underline{4.487}$ & $\underline{0.003}$ & $\underline{\text { Constant }}$ & & $\underline{0.999}$ & $\underline{0.321}$ \\
\hline & & & & $\underline{\mathrm{SRC} 2}$ & $\underline{0.290}$ & 2.620 & $\underline{0.011}$ \\
\hline & & & & $\underline{\mathrm{SRC} 11}$ & $\underline{0.245}$ & $\underline{2.200}$ & $\underline{0.031}$ \\
\hline & & & & $\underline{\text { IMP }}$ & $\underline{0.101}$ & $\underline{0.948}$ & $\underline{0.346}$ \\
\hline & & & & $\underline{\mathrm{REV}}$ & $\underline{-0.031}$ & $\underline{-0.293}$ & $\underline{0.771}$ \\
\hline \multirow[t]{9}{*}{$\underline{\text { Step } 3}$} & $\underline{0.161}$ & $\underline{2.83}$ & $\underline{0.009}$ & $\underline{\text { Constant }}$ & & $\underline{0.94}$ & $\underline{0.352}$ \\
\hline & & & & $\underline{\mathrm{SRC} 2}$ & $\underline{-0.598}$ & $\underline{-1.46}$ & $\underline{0.150}$ \\
\hline & & & & $\underline{\mathrm{SRC} 11}$ & $\underline{0.434}$ & $\underline{1.04}$ & $\underline{0.301}$ \\
\hline & & & & $\underline{\text { IMP }}$ & $\underline{-0.005}$ & $\underline{-0.02}$ & $\underline{0.985}$ \\
\hline & & & & $\underline{\mathrm{REV}}$ & $\underline{-0.183}$ & $\underline{-0.85}$ & $\underline{0.398}$ \\
\hline & & & & $\underline{\text { SRC2*IMP }}$ & $\underline{0.633}$ & $\underline{1.49}$ & $\underline{0.141}$ \\
\hline & & & & $\underline{\text { SRC11*IMP }}$ & $\underline{-0.379}$ & $\underline{-0.89}$ & $\underline{0.379}$ \\
\hline & & & & $\underline{\mathrm{SRC} 2 * \mathrm{REV}}$ & $\underline{0.227}$ & $\underline{1.02}$ & $\underline{0.311}$ \\
\hline & & & & $\underline{\mathrm{SRC} 11 * \mathrm{REV}}$ & $\underline{0.027}$ & $\underline{0.09}$ & $\underline{0.926}$ \\
\hline
\end{tabular}

Table 5. Regression results (delivery policy).

\begin{tabular}{|c|c|c|c|c|c|c|c|}
\hline Model & Adjusted $\mathrm{R}^{2}$ & $\underline{\text { F-value }}$ & Significance F & Variables & $\underline{\text { Standardized } \beta}$ & $\underline{\text { T-value }}$ & Significance \\
\hline \multirow[t]{2}{*}{$\underline{\text { Step } 1}$} & $\underline{0.080}$ & 7.645 & 0.007 & Constant & & 3.343 & $\underline{0.001}$ \\
\hline & & & & $\underline{\mathrm{SRC} 5}$ & $\underline{0.304}$ & $\underline{2.765}$ & $\underline{0.007}$ \\
\hline \multirow[t]{4}{*}{$\underline{\text { Step } 2}$} & $\underline{0.065}$ & 2.775 & $\underline{0.047}$ & Constant & & $\underline{0.959}$ & $\underline{0.340}$ \\
\hline & & & & $\underline{\text { SRC5 }}$ & $\underline{0.283}$ & 2.472 & $\underline{0.016}$ \\
\hline & & & & IMP & $\underline{0.102}$ & $\underline{0.894}$ & $\underline{0.374}$ \\
\hline & & & & $\underline{\mathrm{REV}}$ & -0.012 & $\underline{-0.110}$ & $\underline{0.913}$ \\
\hline \multirow[t]{6}{*}{$\underline{\text { Step } 3}$} & $\underline{0.071}$ & $\underline{2.16}$ & $\underline{0.068}$ & $\underline{\text { Constant }}$ & $\underline{8.455}$ & $\underline{-0,221}$ & $\underline{0.342}$ \\
\hline & & & & $\underline{\text { SRC5 }}$ & $\underline{-0.498}$ & $\underline{-0,045}$ & $\underline{0.669}$ \\
\hline & & & & IMP & -0.123 & $-0,393$ & $\underline{0.914}$ \\
\hline & & & & $\underline{\mathrm{REV}}$ & $\underline{-1.594}$ & $\underline{0,140}$ & $\underline{0.128}$ \\
\hline & & & & $\underline{\text { SRC5*IMP }}$ & $\underline{0.0302}$ & $\underline{0,500}$ & $\underline{0.825}$ \\
\hline & & & & $\underline{\text { SRC } 5 * R E V}$ & $\underline{0.2180}$ & $\underline{-0,221}$ & $\underline{0.126}$ \\
\hline
\end{tabular}


Table 6. Regression results (adaptability).

\begin{tabular}{|c|c|c|c|c|c|c|c|}
\hline Model & $\underline{\text { Adjusted } \mathrm{R}^{2}}$ & F-value & Significance F & $\underline{\text { Variables }}$ & $\underline{\text { Standardized } \beta}$ & T-value & $\underline{\text { Significance }}$ \\
\hline \multirow[t]{4}{*}{ Step 1} & $\underline{0.128}$ & $\underline{4.723}$ & $\underline{0.005}$ & Constant & & 9.235 & $\underline{0.000}$ \\
\hline & & & & $\underline{\mathrm{SRC} 8}$ & $\underline{-0.311}$ & $\underline{-2.666}$ & $\underline{0.009}$ \\
\hline & & & & $\underline{\mathrm{SRC} 9}$ & $\underline{0.232}$ & $\underline{2.040}$ & $\underline{0.045}$ \\
\hline & & & & $\underline{\mathrm{SRC} 12}$ & $\underline{0.347}$ & $\underline{3.104}$ & $\underline{0.003}$ \\
\hline \multirow[t]{6}{*}{$\underline{\text { Step } 2}$} & $\underline{0.143}$ & $\underline{3.546}$ & $\underline{0.006}$ & $\underline{\text { Constant }}$ & & $\underline{4.802}$ & $\underline{0.000}$ \\
\hline & & & & $\underline{\text { SRC8 }}$ & $\underline{-0.259}$ & $\underline{-2.175}$ & $\underline{0.033}$ \\
\hline & & & & $\underline{\text { SRC9 }}$ & $\underline{0.244}$ & $\underline{2.152}$ & $\underline{0.035}$ \\
\hline & & & & $\underline{\mathrm{SRC} 12}$ & $\underline{0.348}$ & $\underline{3.058}$ & $\underline{0.003}$ \\
\hline & & & & $\underline{\text { IMP }}$ & $\underline{-0.188}$ & $\underline{-1.707}$ & $\underline{0.092}$ \\
\hline & & & & $\underline{\mathrm{REV}}$ & $\underline{-0.055}$ & $\underline{-0.493}$ & $\underline{0.623}$ \\
\hline \multirow[t]{12}{*}{$\underline{\text { Step } 3}$} & $\underline{0.094}$ & $\underline{1.72}$ & $\underline{0.089}$ & $\underline{\text { Constant }}$ & & $\underline{2.09}$ & $\underline{0.04}$ \\
\hline & & & & $\underline{\mathrm{SRC} 8}$ & $\underline{-0.505}$ & $\underline{-1.08}$ & $\underline{0.284}$ \\
\hline & & & & $\underline{\text { SRC9 }}$ & $\underline{0.460}$ & $\underline{0.93}$ & $\underline{0.356}$ \\
\hline & & & & $\underline{\mathrm{SRC} 12}$ & $\underline{0.079}$ & $\underline{0.18}$ & $\underline{0.858}$ \\
\hline & & & & $\underline{\text { IMP }}$ & $\underline{-0.175}$ & $\underline{-0.85}$ & $\underline{0.400}$ \\
\hline & & & & $\underline{\mathrm{REV}}$ & $\underline{-0.086}$ & $\underline{-0.59}$ & $\underline{0.556}$ \\
\hline & & & & $\underline{\text { SRC } 8 * I M P}$ & $\underline{0.554}$ & $\underline{1.04}$ & $\underline{0.303}$ \\
\hline & & & & $\underline{\text { SRC9*IMP }}$ & -0.502 & $\underline{-0.97}$ & $\underline{0.336}$ \\
\hline & & & & $\underline{\text { SRC12*IMP }}$ & $\underline{0.022}$ & $\underline{0.05}$ & $\underline{0.961}$ \\
\hline & & & & $\underline{\text { SRC } 8 * R E V}$ & $\underline{-0.154}$ & $\underline{-0.64}$ & $\underline{0.523}$ \\
\hline & & & & $\underline{\mathrm{SRC} 9 * \mathrm{REV}}$ & $\underline{0.187}$ & $\underline{0.84}$ & $\underline{0.403}$ \\
\hline & & & & $\underline{\mathrm{SRC} 12 * \mathrm{REV}}$ & $\underline{0.097}$ & $\underline{0.45}$ & $\underline{0.656}$ \\
\hline
\end{tabular}




\section{Figures}

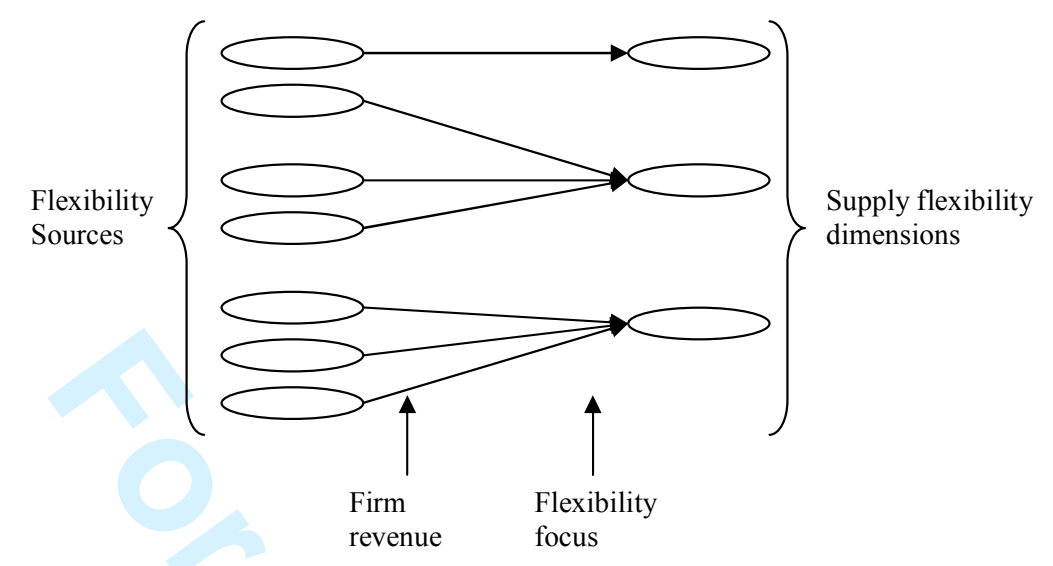

Figure 1. Research Framework.

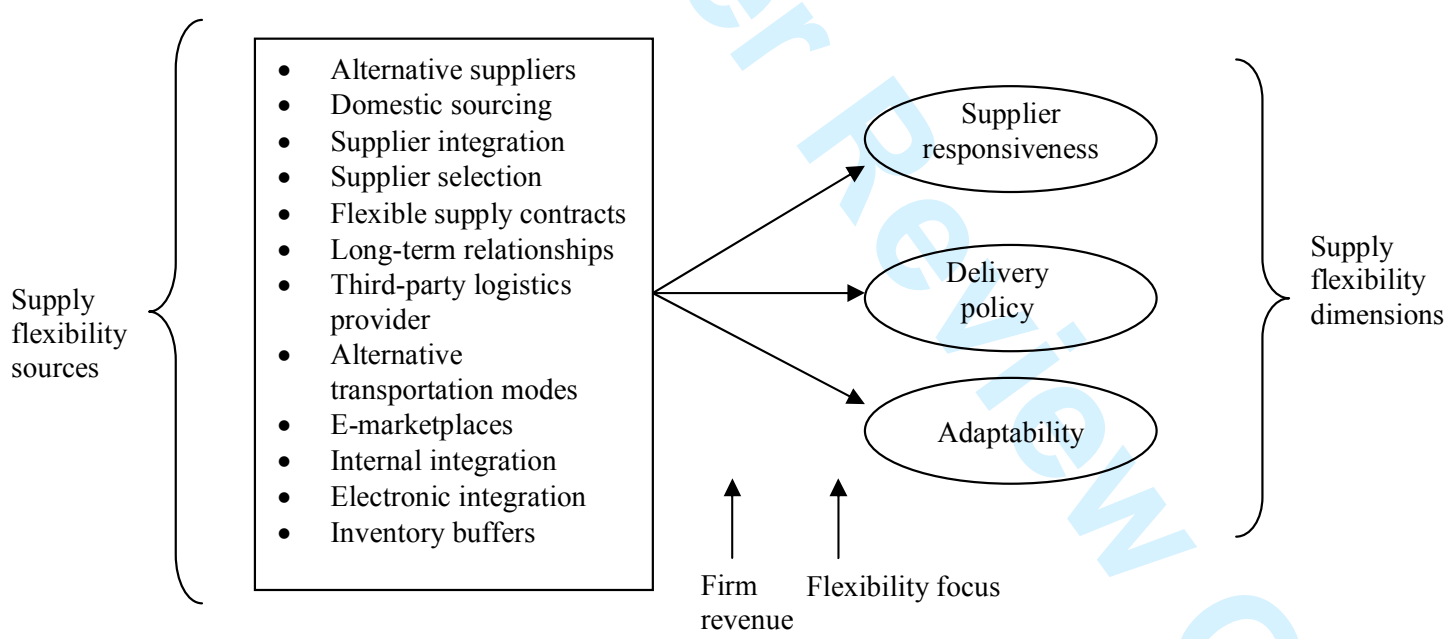

Figure 2. Research model. 


\section{Appendix: Questionnaire}

Please select the purchased material that requires the highest supply flexibility level (defined as the ability of the purchasing function to respond in a timely and cost effective manner to changing requirements of purchased components, in terms of volume, mix and delivery date).

All the following questions refer to this material.

\section{Flexibility sources}

Indicate the frequency you use these practices to increase the supply flexibility of this material $(1=$ never; $10=$ very frequently $)$ :

(1) We use multiple suppliers. (Quayle 1998, Zeng 2000, Minner 2003, Stratton and Warburton 2003)

(2) We use local (i.e. same country) suppliers. (Smith 1999, Christopher 2000, Stratton and Warburton 2003, Bruce et al. 2004, Jin 2004)

(3) We collaborate intensely with the suppliers (sharing information, forming cross-functional teams, joint planning, etc). (Wei and Krajewski 2000, Christopher 2000, Das et al. 2006, Swafford et al. 2006)

(4) We involve the suppliers in joint product development activities. (Womack et al. 1990, Lee 2004)

(5) We select the suppliers based on their flexibility (slack capacity, responsiveness, etc). (Fisher 1997, Nassimbeni 2003, Swafford et al. 2006)

(6) We use flexible contracts (backup agreements, quantity-flexible contracts). (Eppen and Iyer 1997, Wei and Krajewski 2000)

(7) We use long-term relationships with suppliers. (De Toni and Nassimbeni 1999, Bruce et al. 2004)

(8) We collaborate with the inbound logistics provider. (Lee 2002, Lee 2004, Bruce et al. 2004)

(9) We use alternative transportation modes. (Zhang et al. 2002, Pujawan 2004)

(10) We use e-marketplaces to search alternative suppliers. (Kaplan and Sawhney 2000, Peleg et al. 2002, Lee 2002, Saeed et al. 2005) 
(11) We collaborate intensely with other areas within our firm (production, logistics, etc). (Swafford et al. 2006, Narasimhan et al. 2006, Das et al. 2006)

(12) We use Information Technology planning tools (Supply Chain Planning, Suppliers Relationship Management, etc) and/or Electronic Data Interchange (EDI) with the suppliers. (Wei and Krajewski 2000, Stratton and Warburton 2003, Bruce et al. 2004, Chung et al. 2004, Saeed et al. 2005)

(13) We use inventory buffers. (Fisher 1997, Wei and Krajewski 2000, Lee 2002, Stratton and Warburton 2003)

(14) We use other sources of supply flexibility. Which one (s)?

\section{Supply flexibility}

Using a 10 -point scale $(1=$ low; $10=$ high $)$, please evaluate the level of the following characteristics associated with the procurement/sourcing function in your business unit:

(1) Range of supplier delivery frequencies (daily, weekly, etc). (Swafford et al., 2006)

(2) Range of possible order sizes from suppliers. (Swafford et al., 2006)

(3) Extent to which supplier lead-time can be expedited/changed. (Swafford et al., 2006)

(4) Extent to which supplier short-term capacity can be influenced. (Swafford et al., 2006)

Using a 10-point scale ( $1=$ low; $10=$ high), please indicate the average level of cost/time associated with engaging in the following procurement/sourcing activities in your business unit:

(1) Change quantity of supplier's order. (Swafford et al., 2006)

(2) Change specification/configuration of supplier's order. (Swafford et al., 2006)

(3) Influence supplier's ability to implement engineering change orders. (Swafford et al., 2006)

(4) Change delivery times of orders placed with suppliers. (Swafford et al., 2006)

(5) Influence supplier's short-term capacity. (Swafford et al., 2006)

\section{Flexibility focus}


Using a 10-point scale ( $1=$ unimportant; $10=$ critical $)$, please indicate the level of the following characteristic:

(1) Which is the importance of flexibility in the sourcing strategy of your business unit? (Vickery et al. 1999)

4. Annual revenue (million euros)
(1) Less than 1
(2) Between 1 and 49
(3) Between 50 and 99
(4) Between 100 and 499
(5) More than 500 